\title{
DAMPAK ALIH FUNGSI LAHAN SAWAH TERHADAP KONDISI SOSIAL EKONOMI MASYARAKAT KECAMATAN BAITUSSALAM KABUPATEN ACEH BESAR
}

\author{
(Impact Of Paddy Fields Function On Community Socio-Economic Conditions Of Baitussalam \\ District, Aceh Besar Regency)
}

\author{
Yasfir Ma'arif ${ }^{1}$, Teuku Fauzi $^{1}$, Safrida $^{1 *}$ \\ ${ }^{1}$ Program Studi Agribisnis, Fakultas Pertanian, Universitas Syiah Kuala
}

\begin{abstract}
Abstrak Pertumbuhan penduduk dan dinamika pembangunan telah menggeser pemanfaatan lahan yang akhirnya menimbulkan kompleksitas permasalahan lahan yang semula berfungsi sebagai media bercocok tanam (pertanian), berangsur-angsur berubah menjadi multifungsi pemanfaatan. Berubahnya pemanfaatan lahan pertanian ke non pertanian dapat disebut juga sebagai alih fungsi lahan. Kabupaten Aceh Besar adalah salah satu kabupaten yang terus menghadapi permasalahan alih fungsi lahan, khususnya lahan sawah. Alih fungsi lahan ini mengakibatkan luas lahan sawah di Aceh Besar terus menurun. Lahan yang paling banyak mengalami alih fungsi lahan adalah jenis lahan sawah yang menjadi lahan non pertanian. Penelitian ini bertujuan untuk mengidentifikasi faktor-faktor yang menyebabkan terjadinya alih fungsi lahan sawah dan mengidentifikasi dampak sosial dan ekonomi yang dialami petani mantan pemilik lahan akibat alih fungsi lahan sawah menjadi lahan non pertanian. Berdasarkan hasil regresi secara parsial dari analisis regresi faktor harga jual, kebutuhan hidup dan kondisi lahan berpengaruh nyata terhadap konversi lahan sawah di Kecamatan Baitussalam Kabupaten Aceh Besar. Bedasarkan hasil regresi secara serempak dari hasil regresi didapatkan bahwa harga jual, kebutuhan hidup dan kondisi lahan secara serempak mempengaruhi konversi lahan sawah di Kecamatan Baitussalam Kabupaten Aceh Besar. Berdasarkan isu dampak sosial sebagai akibat alih fungsi lahan di lihat dari keinginan kondisi lama, meningkatkan rasa kerjasama dan kekeluargaan, serta kemampuan memenuhi kebutuhan keluarga mendapatkan hasil yang positif dengan nilai $\geq 50 \%$. Berdasarkan isu dampak ekonomi sebagai akibat alih fungsi lahan di lihat dari peningkatan pendapatan mendapatkan hasil yang positif dengan nilai $\geq 50 \%$.
\end{abstract}

Kata kunci : Alih fungsi lahan, dampak sosial, dampak ekonomi.

Abstract Population growth and the dynamics of development have shifted land use which eventually led to the complexity of the problem of land that used to function as a farming medium (agriculture), gradually becoming a multifunctional use. Changing the use of agricultural land to non-agriculture can also be referred to as land conversion. Aceh Besar District is one of the districts that continues to face the problem of land conversion, especially rice fields. The conversion of this land function has caused the area of paddy fields in Aceh Besar to continue to decline. The land that has experienced the most land use change is the type of rice field that becomes non-agricultural land. This study aims to identify the factors that cause the conversion of paddy fields and identify the social and economic impacts experienced by farmers former landowners due to the conversion of paddy fields to non-agricultural land. Based on the partial regression results from the regression analysis, the factors of selling price, life necessity and land conditions have a significant effect on the conversion of paddy fields in Baitussalam District, Aceh Besar District. Based on the simultaneous regression results from the regression results, it was found that the selling price, life needs and land conditions simultaneously affected the conversion of paddy fields in Baitussalam District, Aceh Besar District. Based on the issue of social impacts as a result of land use change seen from the desires of the old conditions, increasing the sense of cooperation and kinship, as well as the ability to meet family needs get positive results with a value of $\geq 50 \%$. Based on the issue of economic impact as a result of the transfer of land functions, it can be seen from the increase in income that has a positive result with a value of $\geq 50 \%$.

Keywords: Development of cloves, problems, motivation of farmers, driving factors, inhibiting factors.

*Corresponding author : safrida@unsyiah.ac.id 


\section{PENDAHULUAN}

Pertumbuhan penduduk dan dinamika pembangunan telah menggeser pemanfaatan lahan yang akhirnya menimbulkan kompleksitas permasalahan lahan yang semula berfungsi sebagai media bercocok tanam (pertanian), berangsur-angsur berubah menjadi multifungsi pemanfaatan. Berubahnya pemanfaatan lahan pertanian ke non pertanian dapat disebut juga sebagai alih fungsi lahan.

Lestari (2009) mendefinisikan alih fungsi lahan atau lazimnya disebut sebagai konversi lahan adalah perubahan fungsi sebagian atau seluruh kawasan lahan dari fungsinya semula (seperti yang direncanakan) menjadi fungsi lain yang berdampak negatif (masalah) terhadap lingkungan dan potensi lahan itu sendiri.

Kabupaten Aceh Besar adalah salah satu kabupaten yang terus menghadapi permasalahan alih fungsi lahan, khususnya lahan sawah. Alih fungsi lahan ini mengakibatkan luas lahan sawah di Aceh Besar terus menurun. Lahan yang paling banyak mengalami alih fungsi lahan adalah jenis lahan sawah yang menjadi lahan non pertanian.

Tabel 1. Luas Alih Fungsi Lahan Sawah di Kabupaten Aceh Besar Tahun 2014

\begin{tabular}{clccc}
\hline No. & \multicolumn{1}{c}{ Kecamatan } & $\begin{array}{c}\text { Luas Lahan } \\
\text { Sawah (Ha) }\end{array}$ & $\begin{array}{c}\text { Luas Alih Fungsi } \\
\text { Lahan (Ha) }\end{array}$ & $\begin{array}{c}\text { Sisa Lahan } \\
\text { Sawah (Ha) }\end{array}$ \\
\hline 1. & Lhoong & 1.004 & 25 & 979 \\
2. & Lhoknga & 1.010 & 15 & 995 \\
3. & Leupung & 535 & 10 & 525 \\
4. & Indrapuri & 2.474 & 17 & 2.457 \\
5. & Kuta Cot Glie & 1.848 & 5 & 1.843 \\
6. & Seulimeum & 3.523 & 5 & 3.518 \\
7. & Kota Jantho & 1.155 & 0 & 1.155 \\
8. & Lembah Seulawah & 875 & 5 & 870 \\
9. & Mesjid Raya & 47 & 20 & 27 \\
10. & Darussalam & 2.346 & 7 & 2.339 \\
11. & Baitussalam & 512 & 210 & 302 \\
12. & Kuta Baro & 2.195 & 38 & 2.157 \\
13. & Montasik & 2.277 & 25 & 2.252 \\
14. & Ingin Jaya & 2.360 & 50 & 2.310 \\
15. & Krueng Barona Jaya & 560 & 110 & 450 \\
16. & Suka Makmur & 1.943 & 5 & 1.938 \\
17. & Kuta Malaka & 642 & 2 & 640 \\
18. & Simpang Tiga & 1.305 & 9 & 1.296 \\
19. & Darul Imarah & 681 & 30 & 651 \\
20. & Darul Kamal & 476 & 10 & 466 \\
21. & Peukan Bada & 815 & 50 & 765 \\
22. & Pulo Aceh & 275 & 0 & 275 \\
23. & Blang Bintang & 1.563 & $\mathbf{6 7 3}$ & $\mathbf{2 9 . 7 4 8}$ \\
\hline Jumlah & $\mathbf{3 0 . 4 2 1}$ & 2538 \\
\hline
\end{tabular}

Sumber : Dinas Pertanian Tanaman Pangan dan Hortikultura Aceh Besar, 2014

Adapun beberapa indikator dari dampak sosial dan ekonomi terhadap alih fungsi lahan sebagai berikut:

Dampak Alih Fungsi Lahan Sawah Terhadap Kondisi Sosial Ekonomi Masyarakat Kecamatan Baitussalam 220

Kabupaten Aceh Besar (Yasfir Ma'arif, Safrida, Teuku Fauzi).

Jurnal Ilmiah Mahasiswa Pertanian, Vol. 3, No. 4, November 2018: 219-226 
1. Keinginan meninggalkan kondisi lama

2. Keinginan bertani di tempat lain yang lebih produktif

3. Keinginan mengembangkan usaha

4. Kerjasama dan kekeluargaan masyarakat

5. Kemampuan memenuhi kebutuhan dalam keluarga

6. Jumlah pendapatan

Alih fungsi lahan sawah dilakukan secara langsung oleh petani pemilik lahan ataupun tidak langsung oleh pihak lain yang sebelumnya diawali dengan transaksi jual beli lahan sawah. Proses alih fungsi lahan sawah pada umumnya berlangsung cepat jika akar penyebabnya terkait dengan upaya pemenuhan kebutuhan sektor ekonomi lain yang menghasilkan surplus ekonomi (land rent) jauh lebih tinggi (misalnya untuk pembangunan kawasan industri, kawasan perumahan, dan sebagainya) atau untuk pemenuhan kebutuhan mendasar prasarana umum yang diprogramkan pemerintah, atau untuk lahan tempat tinggal pemilik lahan yang bersangkutan (Murniningtyas, 2007).

Berdasarkan latar belakang di atas lahan sawah di Kecamatan Baitussalam Kabupaten Aceh Besar yang terus mengalami penigkatan alih fungsi ke lahan nonpertanian. Oleh sebab itu penulis tertarik untuk melakukan penelitian mengenai "Dampak Alih Fungsi Lahan Sawah Terhadap Kondisi Sosial Ekonomi Masyarakat Kecamatan Baitussalam Kabupaten Aceh Besar.”

\section{Identifikasi Masalah}

1. Faktor-faktor apa saja yang menyebabkan terjadinya alih fungsi lahan sawah?

2. Bagaimana dampak sosial yang dialami petani mantan pemilik lahan akibat alih fungsi lahan sawah menjadi lahan non pertanian?

3. Bagaimana dampak ekonomi yang dialami petani mantan pemilik lahan akibat alih fungsi lahan sawah menjadi lahan non pertanian?

\section{Tujuan Penelitian}

1. Mengidentifikasi faktor-faktor yang menyebabkan terjadinya alih fungsi lahan sawah

2. Mengidentifikasi dampak sosial yang dialami petani eks-pemilik lahan akibat alih fungsi lahan sawah menjadi lahan non pertanian

3. Mengidentifikasi dampak ekonomi yang dialami petani eks-pemilik lahan akibat alih fungsi lahan sawah menjadi lahan non pertanian

\section{METODE PENELITIAN}

Penentuan kecamatan dilakukan dengan sengaja (purposive sampling) memilih kecamatan yang paling banyak mengalami konversi lahan sesuai dengan data pada Tabel Luas Alih Fungsi Lahan Sawah di Kabupaten Aceh Besar Tahun 2014. yaitu Kecamatan Baitussalam. Berdasarkan Kantor Camat Baitussalam (2013), jumlah populasi petani yang mengkonversi lahan adalah sebesar 330 petani. Jumlah sampel yang akan mewakili populasi diambil sampel fraksi sebesar $10 \%$ dari responden yang melakukan alih fungsi lahan sawah menjadi lahan non pertanian, dimana $\mathrm{f}_{2}=\mathrm{n}_{\mathrm{i}} / \mathrm{N}_{\mathrm{i}}$, maka jumlah sampel yang di ambil adalah 30 orang.

\section{Model Analisis}

\section{Data Dan Sumber Data}

1. Data primer adalah data yang diperoleh langsung dengan melakukan wawancara dan observasi di tempat penelitian. 
2. data sekunder yang diperoleh dari berbagai literatur perpustakaan seperti buku - buku, hasil penelitian (jurnal) sebelumnya, berbagai tulisan lainnya dan badan instansi yang terkait seperti Badan Pusat Statistik (BPS).

\section{Hipotesis 1}

Dimana:

$$
\mathbf{Y}=\boldsymbol{\alpha}+\boldsymbol{\beta}_{1} \mathbf{X}_{1}+\boldsymbol{\beta}_{2} \mathbf{X}_{2}+\boldsymbol{\beta}_{3} \mathbf{X}_{3}+e
$$

$\mathrm{Y}=$ konversi lahan sawah (meter)

$\alpha=$ konstanta

$\mathrm{X}_{1}=$ harga jual $(\mathrm{Rp} / \mathrm{meter})$

$\mathrm{X}_{2}=$ kebutuhan hidup $(\mathrm{Rp} / \mathrm{bulan})$

$\mathrm{X}_{3}=$ kondisi lahan (skor)

$\mathrm{e}=$ error

\section{Uji-F Statistik}

Untuk mengetahui peranan variabel yang mempengaruhi terhadap variabel yang dipengaruhi secara serempak (bersama-sama), maka penelitian ini menggunakan uji $\mathrm{F}$ dengan rumus (Sudjana, 2005) sebagai berikut:

Dimana:

$$
\mathbf{F}_{\text {hitung }}=\frac{\mathbf{R}^{2} / \mathbf{k}}{\left(\mathbf{1}-\mathbf{R}^{2}\right) /(\mathbf{n}-\mathbf{k}-\mathbf{1})}
$$

$\mathrm{R}^{2}=$ koefisien determinasi

$\mathrm{k}$ = banyaknya variabel bebas

$\mathrm{n}=$ jumlah sampel

$\mathrm{F}_{\text {hitung }}>\mathrm{F}_{\text {tabel }}$, pada taraf nyata 0,05 maka $\mathrm{H}_{\mathrm{a}}$ diterima dan $\mathrm{H}_{0}$ ditolak, artinya variabelvariabel yang mempengaruhi berpengaruh secara nyata (signifikan) terhadap variabel yang dipengaruhi.

$\mathrm{F}_{\text {hitung }} \leq \mathrm{F}_{\text {tabel }}$, pada taraf nyata 0,05 maka $\mathrm{H}_{\mathrm{a}}$ ditolak dan $\mathrm{H}_{0}$ diterima, artinya variabelvariabel yang mempengaruhi tidak berpengaruh secara nyata (non signifikan) terhadap variabel yang dipengaruhi.

\section{Uji-t Statistik}

Untuk mengetahui pengaruh masing-masing variabel yang mempengaruhi terhadap variabel yang dipengaruhi secara parsial (terpisah), maka digunakan uji t dengan menggunakan rumus (Sudjana, 2005) sebagai berikut:

Dimana:

$$
t_{\text {hitung }}=\frac{a_{i}}{S E_{a i}}
$$

$a_{i} \quad=$ koefisien regresi yang dicari

$S E a_{i}=$ standar error

$t_{\text {tabel }}>\mathrm{t}_{\text {hitung, }}$ pada taraf nyata 0,05 maka $\mathrm{H}_{\mathrm{a}}$ diterima dan $\mathrm{H}_{0}$ ditolak, artinya variabelvariabel yang mempengaruhi berpengaruh secara nyata (signifikan) terhadap variabel yang dipengaruhi.

$\mathrm{t}_{\text {tabel }} \leq \mathrm{t}_{\text {hitung, }}$, pada taraf nyata 0,05 maka $\mathrm{H}_{\mathrm{a}}$ ditolak dan $\mathrm{H}_{0}$ diterima, artinya variabelvariabel yang mempengaruhi tidak berpengaruh secara nyata (non signifikan) terhadapat variabel yang dipengaruhi.

Dampak Alih Fungsi Lahan Sawah Terhadap Kondisi Sosial Ekonomi Masyarakat Kecamatan Baitussalam 222 Kabupaten Aceh Besar (Yasfir Ma'arif, Safrida, Teuku Fauzi).

Jurnal Ilmiah Mahasiswa Pertanian, Vol. 3, No. 4, November 2018: 219-226 


\section{Uji Determinasi $\mathbf{R}^{2}$}

Untuk mengetahui keeratan antara bariabel yang dipengaruhi dan variabel yang dipengaruhi digunakan koefisien determinasi $\left(\mathrm{R}^{2}\right)$ dengan menggunakan rumus (Sudjana, 2005) sebagai berikut:

Dimana:

$$
\mathbf{R}^{2}=\frac{j k_{(r e g)}}{\sum y i^{2}}
$$

$j k_{(r e g)}=$ jumlah kuadrat regresi

$\sum y i^{2}=$ jumlah kuadrat total

\section{Hipotesis 2 dan 3}

Untuk menguji hipotesis 2 dan 3 digunakan metode analisis deskriptif-kualitatif. Fokusnya adalah dampak kondisi sosial ekonomi serta faktor faktor yang menyebabkan terjadinya alih fungsi lahan sawah.

\section{Karakteristik Responden}

\section{HASIL DAN PEMBAHASAN}

\section{Umur}

Tabel 2. Karakteristik Responden Berdasarkan Umur

\begin{tabular}{cccc}
\hline No. & $\begin{array}{c}\text { Umur } \\
\text { (Tahun) }\end{array}$ & $\begin{array}{c}\text { Jumlah Responden } \\
\text { (Orang) }\end{array}$ & $\begin{array}{c}\text { Persentase } \\
(\mathbf{\%})\end{array}$ \\
\hline 1. & $30-39$ & 6 & 20 \\
2. & $40-49$ & 11 & 37 \\
3. & $50-59$ & 13 & 43 \\
\hline & Total & $\mathbf{3 0}$ & $\mathbf{1 0 0}$ \\
\hline
\end{tabular}

\section{Sumber: Data Primer, 2016 (Diolah)}

Berdasarkan tabel tersebut dapat dilihat bahwa pemilik lahan usia 50 tahun keatas lebih memilih untuk mengkonversi lahan, daripada pemilik lahan usia dibawahnya. Hal ini dikarenakan pemilik lahan usia 50 tahun keatas biasanya tidak memiliki fisik yang cukup kuat untuk kembali bekerja di lahan, sehingga para pemilik lahan tersebut lebih memilih untuk melakukan alih fungsi lahan untuk memenuhi kebutuhan hidupnya.

\section{Pendidikan}

Tabel 3. Karakteristik Responden Berdasarkan Pendidikan

\begin{tabular}{cccc}
\hline No. & Pendidikan & $\begin{array}{c}\text { Jumlah Responden } \\
\text { (Orang) }\end{array}$ & $\begin{array}{c}\text { Persentase } \\
(\boldsymbol{\%})\end{array}$ \\
\hline 1. & SMP $(9$ tahun $)$ & 12 & 40 \\
2. & SMA (12 tahun) & 8 & 27 \\
3. & S1 ( > 12 tahun) & 10 & 33 \\
\hline \multicolumn{2}{c}{ Total } & $\mathbf{3 0}$ & $\mathbf{1 0 0}$ \\
\hline
\end{tabular}

Sumber: Data Primer, 2016 (Diolah)

Berdasarkan tabel dapat dilihat bahwa umumnya masyarakat di Kecamatan Baitussalam Kabupaten Aceh Besar masih kurang memahami pentingnya pendidikan, karena sebanyak 12 dari 30 responden penelitian masih berstatus pendidikan terakhir SMP, sehingga kurangnya pengetahuan juga bisa mengakibatkan para pemilik lahan melakukan alih fungsi lahan karena menganggap lahannya tidak produktif lagi untuk dijadikan lahan pertanian.

Dampak Alih Fungsi Lahan Sawah Terhadap Kondisi Sosial Ekonomi Masyarakat Kecamatan Baitussalam 223 


\section{Jumlah Tanggungan}

Tabel 4. Karakteristik Responden Berdasarkan Jumlah Tanggungan

\begin{tabular}{cccc}
\hline No. & $\begin{array}{c}\text { Jumlah Tanggungan } \\
\text { (Orang) }\end{array}$ & $\begin{array}{c}\text { Jumlah Responden } \\
\text { (Orang) }\end{array}$ & $\begin{array}{c}\text { Persentase } \\
(\boldsymbol{\%})\end{array}$ \\
\hline 1. & $1-2$ & 9 & 30 \\
2. & $3-4$ & 9 & 30 \\
3. & $>4$ & 12 & 40 \\
\hline \multicolumn{2}{c}{ Total } & $\mathbf{3 0}$ & $\mathbf{1 0 0}$ \\
\hline
\end{tabular}

Sumber: Data Primer, 2016 (Diolah)

Berdasarkan tabel diatas menyatakan bahwa 12 dari 30 responden di Kecamatan Baitussalam Kabupaten Aceh Besar memiliki jumlah tanggungan lebih dari 4. Menurut Nursanti (2011), jumlah tanggungan dalam suatu rumah tangga dapat mempengaruhi seseorang dalam bekerja dan mencari nafkah untuk memenuhi kebutuhan hidupnya dan keluarga. Karena banyaknya jumlah tanggungan yang dimiliki oleh para pemilik lahan, menyebabkan mereka melakukan alih fungsi lahan karena keuntungan yang lebih banyak dan lebih cepat dibandingkan dengan hanya bercocok tanam di lahan miliknya.

\section{Model Regresi Linear Berganda}

\section{Tabel 5. Model Regresi Linear Berganda}

\begin{tabular}{clccc}
\hline No. & \multicolumn{1}{c}{ Variabel } & Koefisien Regresi & thitung & F $_{\text {hitung }}$ \\
\hline 1. & Konversi lahan sawah $(\mathrm{Y})$ & 1578,071 & 6,656 & \\
2. & Harga jual $\left(\mathrm{X}_{1}\right)$ & $-2,639$ & 3,556 & 7,443 \\
3. & Kebutuhan hidup $\left(\mathrm{X}_{2}\right)$ & 7,964 & 3,575 & \\
4. & Produktivitas lahan $\left(\mathrm{X}_{3}\right)$ & 14,313 & 0,230 & \\
\hline 5. & $\mathbf{t}_{\text {tabel }}=1,708$ & & \\
\hline 6. & $\mathbf{F}_{\text {tabel }}=2,98$ & \\
\hline 7. & Determinasi $\mathbf{R}^{2}=0,642$ & \\
\hline
\end{tabular}

Sumber: Data Primer, 2016 (Diolah)

$$
Y=1578,071-2,639 X_{1}-7,964 X_{2}+14,313 X_{3}
$$

Berdasarkan model regresi linear berganda tersebut, maka dapat dijelaskan:

1. Apabila harga jual, kebutuhan hidup dan produktivitas lahan diasumsikan berada pada keadaan yang konstan (tetap), maka konversi lahan sawah adalah seluas 1578,071 meter (1,57 hektar).

2. $\quad F_{\text {hitung }}>F_{\text {tabel }}(7,443>2,98)$ yang artinya, harga jual, kebutuhan hidup dan produktivitas lahan secara serempak mempengaruhi konversi lahan sawah di Kecamatan Baitussalam Kabupaten Aceh Besar

3. Nilai $\mathrm{X} 1=(-2,639)$ artinya Setiap kenaikan 1 satuan nilai harga jual, maka akan mengurangi konversi lahan seluas 2,639 meter. Dengan nilai $t_{\text {hitung }}>t_{\text {tabel }}(3,556>1,708)$ yang menunjukkan bahwa $\mathrm{H}_{\mathrm{a}}$ diterima dan $\mathrm{H}_{0}$ ditolak, artinya harga jual berpengaruh nyata terhadap konversi lahan sawah di Kecamatan Baitussalam Kabupaten Aceh Besar.

4. Nilai x2 $=(7,964)$, artinya setiap kenaikan 1 satuan nilai kebutuhan hidup, maka akan meningkatkan konversi lahan sawah seluas 7,964 meter. Dengan nilai thitung $>t_{\text {tabel }}(3,575$ $>1,708$ ) yang menunjukkan bahwa $\mathrm{H}_{\mathrm{a}}$ diterima dan $\mathrm{H}_{0}$ ditolak, artinya demikian kebutuhan

Dampak Alih Fungsi Lahan Sawah Terhadap Kondisi Sosial Ekonomi Masyarakat Kecamatan Baitussalam 224 Kabupaten Aceh Besar (Yasfir Ma'arif, Safrida, Teuku Fauzi).

Jurnal Ilmiah Mahasiswa Pertanian, Vol. 3, No. 4, November 2018: 219-226 
hidup berpengaruh nyata terhadap konversi lahan sawah di Kecamatan Baitussalam Kabupaten Aceh Besar.

5. Nilai $x 3=(14,313)$, artinya setiap kenaikan 1 satuan produktivitas lahan, maka akan meningkatkan konversi lahan sawah seluas 14,313 meter. Dengan nilai $t_{\text {hitung }} \leq t_{\text {tabel }}(0,230$ $\leq 1,708$ ) yang menunjukkan bahwa $\mathrm{H}_{\mathrm{a}}$ diterima dan $\mathrm{H}_{0}$ ditolak, artinya produktivitas lahan tidak berpengaruh nyata terhadap konversi lahan sawah di Kecamatan Baitussalam Kabupaten Aceh Besar.

\section{Dampak Sosial dari Alih Fungsi Lahan di Kecamatan Baitussalam Kabupaten Aceh Besar}

Berdasarkan kajian responden dampak sosial dari alih fungsi lahan di kecamatan baitussalam kabupaten aceh besar terdapat 5 faktor yang mempengaruhi dampak sosial didaerah penelitian, yaitu:

1. Kebutuhan terhadap barang mewah sebanyak $46 \%$

2. Keinginan meninggalkan kondisi lama sebanyak $50 \%$

3. Keinginan mengembangkan usaha sebanyak $37 \%$

4. Kerjasama dan kekeluargaan masyarakat sebanyak $70 \%$

5. Kemampuan memenuhi kebutuhan dalam keluarga sebanyak $74 \%$

\section{Dampak Ekonomi dari Alih Fungsi Lahan di Kecamatan Baitussalam Kabupaten Aceh Besar}

Berdasarkan kajian responden dampak ekonomi dari alih fungsi lahan di kecamatan baitussalam kabupaten aceh besar terdapat 4 faktor yang mempengaruhi dampak ekonomi didaerah penelitian, yaitu:

1. Peningkatan pendapatan sebanyak $73 \%$

2. Kemampuan investasi sebanyak $37 \%$

3. Kemampuan menabung sebanyak $27 \%$

4. Kemampuan usaha sebanyak $37 \%$

\section{Kesimpulan}

\section{KESIMPULAN DAN SARAN}

1. Berdasarkan hasil regresi secara parsial dari analisis regresi faktor harga jual, kebutuhan hidup dan kondisi lahan berpengaruh nyata terhadap konversi lahan sawah di Kecamatan Baitussalam Kabupaten Aceh Besar.

2. Bedasarkan hasil regresi secara serempak dari hasil regresi didapatkan bahwa harga jual, kebutuhan hidup dan kondisi lahan secara serempak mempengaruhi konversi lahan sawah di Kecamatan Baitussalam Kabupaten Aceh Besar.

3. Bedasarkan hasil regresi didapatkan bahwa $87,1 \%$ harga jual, kebutuhan hidup dan kondisi lahan mempengaruhi konversi lahan sawah, sedangkan 12,9\% dipengaruhi oleh variable lain diluar model.

4. Berdasarkan isu dampak sosial sebagai akibat alih fungsi lahan di lihat dari keinginan kondisi lama, meningkatkan rasa kerjasama dan kekeluargaan, serta kemampuan memenuhi kebutuhan keluarga mendapatkan hasil yang positif dengan nilai $\geq 50 \%$.

5. Berdasarkan isu dampak ekonomi sebagai akibat alih fungsi lahan di lihat dari peningkatan pendapatan mendapatkan hasil yang positif dengan nilai $\geq 50 \%$.

Saran

Dampak Alih Fungsi Lahan Sawah Terhadap Kondisi Sosial Ekonomi Masyarakat Kecamatan Baitussalam 225 Kabupaten Aceh Besar (Yasfir Ma’arif, Safrida, Teuku Fauzi).

Jurnal Ilmiah Mahasiswa Pertanian, Vol. 3, No. 4, November 2018: 219-226 
1. Pemerintah agar lebih serius dalam menanggapi permasalahan terkait dengan alih fungsi lahan, utamanya dalam menetepkan suatu kebijakan dan aturan perundang-undangan.

2. Masyarakat hendaknya menyadari pentingnya lahan pertanian untuk memenuhi kebutuhan pangan penduduk.

\section{DAFTAR PUSTAKA}

Ilham, 2003. Perkembangan dan Faktor-Faktor Yang Mempengaruhi Konversi Lahan Sawah Serta Dampak Ekonominya. IPB Press. Bogor

Irawan, B. 2005. Konversi Lahan Sawah Menimbulkan Dampak Negatif Bagi Ketahanan Pangan dan Lingkungan. Pusat Analisis Sosial Ekonomi dan Kebijakan Pertanian. Bogor. http://pustaka.litbang.deptan.go.id diakses 20 April 2015.

International Association for Impact Assessment. 2003. Social Impact Assessment International Principles. IAIA. Special Publications Series No.2. Fargo, US.

Kustiawan, Iwan. 1997. Permasalahan Konversi Lahan Pertanian dan Implikasinya Terhadap Penataan Ruang Wilayah Studi Kasus : Wilayah Pantai Utara Jawa. Jurnal PWK Vol.8. No 1/Januari 1997.

Lestari, T. 2009. Dampak Konversi Lahan Pertanian Bagi Taraf Hidup Petani. Skripsi. Institut Pertanian Bogor. Bogor. http://kolokiumkpmipb.wordpress.com diakses 20 April 2015

Murniningtyas, E, 2007. Strategi Pengendalian Alih Fungsi Lahan Pertanian. Direktorat Pangan dan Pertanian Kementrian Perncanaan Pembangunan nasional. Jakarta.

Mustopa, Zaenil. 2011. Analisis Faktor - Faktor Yang Mempengaruhi Alih Fungsi Lahan Pertanian Di Kabupaten Demak. Fakultas Ekonomi Universitas Diponegoro. Semarang.

Nursanti, I. 2011. Kajian Faktor-Faktor yang Mempengaruhi Konversi Lahan Sawah Menjadi Lahan Non Pertanian di Kabupaten Aceh Besar. Thesis. Universitas Syiah Kuala. Banda Aceh.

Sudjana. 2005. Metode Statistika. Tarsito. Bandung

Dampak Alih Fungsi Lahan Sawah Terhadap Kondisi Sosial Ekonomi Masyarakat Kecamatan Baitussalam 226 Kabupaten Aceh Besar (Yasfir Ma’arif, Safrida, Teuku Fauzi).

Jurnal Ilmiah Mahasiswa Pertanian, Vol. 3, No. 4, November 2018: 219-226 